\title{
Efficiency assessment of Ultra-filtration pretreatment prior to Reverse Osmosis separation of contaminated natural water
}

\author{
T.A.Trifonova ${ }^{1}$, A.A. Povorov $^{2}$, L.A. Shirkin ${ }^{3}$, O.G. Selivanov ${ }^{4}$, M.E Ilina ${ }^{5}$ \\ ${ }^{1}$ Vladimir State University named after A. G. and N. G. Stoletovs, Vladimir, Russian Federation \\ tatrifon@mail.ru \\ ${ }^{2}$ BMT LLC, Vladimir, Russian Federation \\ vladimir@vladbmt.ru \\ ${ }^{3}$ Vladimir State University named after A. G. and N. G. Stoletovs, Vladimir, Russian Federation \\ shirkin76@mail.ru \\ ${ }^{4}$ Vladimir State University named after A. G. and N. G. Stoletovs, Vladimir, Russian Federation, \\ selivanov6003@mail.ru \\ ${ }^{5}$ Vladimir State University named after A. G. and N. G. Stoletovs, Vladimir, Russian Federation \\ ilina4@mail.ru
}

\begin{abstract}
The paper presents the efficiency assessment results of polluted natural water pretreatment applying various pressure ultra-filtration membrane elements prior to reverse osmosis separation. The research was carried out using pilot ultra-filtration plant equipped with pressure ceramic, hollow fiber membranes made of polysulphone and polyvinylidene fluoride by various manufacturers. The study revealed that all membrane elements provide high purification degree regarding suspended substances $>99.9 \%$, total iron - by 80 $\%$, petroleum products $>90 \%$, and non-ionic surfactants $>$ $84 \%$. The final performance of pressure tubular ceramic and hollow fiber elements made of polysulphone and polyvinylidene fluoride is almost identical. The comparison of performance recovery for clean municipal supply water after chemical washing proved that polysulphone-based pressure fiber element demonstrated the best recovery. Thus, ultra-filtration polysulphone pressure membrane elements revealed the best result in the treatment of contaminated natural water, represented by solid waste landfill leachate.
\end{abstract}

Key words: contaminated natural water, pretreatment, Ultra-filtration, Reverse Osmosis, membrane pressure ceramic and hollow fiber elements, specific filtration velocity

\section{INTRODUCTION}

Nowadays ultra-filtration is widely used for removing toxic pollutants from industrial and household waste water [1-3], for treating natural surface and underground waters, removing high-molecular organic matters, suspended, colloidal, microbiological and organic compounds from water [4-6].
The increasing role of UF plants also depends on poor water quality in such industries as mechanical engineering, heat power engineering, micro- and radio electronics, food, textile industries and electroplating. In connection with the strict standard regulations for water quality used in various technological and production operations at these enterprises, reverse osmosis systems are used for water treatment. RO plants provide producing water of the required quality, but on the condition that the initial water fed to the reverse osmosis membrane plant is to be pre-prepared in order to meet certain requirements and criteria.

The requirements apply to such parameters as suspended and colloidal substances, water hardness, color, petroleum's, surfactants, $\mathrm{pH}$, etc. There is a number of indices and criteria for evaluating the source water quality fed to the Reverse Osmosis plants. So, the level of colloidal and suspended substances in water is determined by the sediment density index SDI, and its value for water fed to the RO plant is set to be lower than 3. It is not allowed to operate RO systems with an SDI over 5. Membrane ultrafiltration elements can solve the problem of water pretreatment prior to RO. The number of membrane elements manufacturers and membrane types is growing, but choosing the suitable membrane elements, taking into account water treatment of specific composition and maximum specific performance and recovery of performance characteristics after chemical washing is an important and urgent challenge. Heavy fouling of ultrafiltration membranes remains a serious problem thus in order to maintain membrane long-term operation, the scheme of contaminated water media pre-treatment may include various systems: coagulation-ultra-filtration (CUF), granular filter - ultra-filtration, ozonation - Ultra-filtration [7-9]. 
The research objective is to determine UF pretreatment efficiency of contaminated natural waters by various pressure ultra-filtration membrane elements prior to Reverse Osmosis separation.

\section{RESEARCH OBJECTS AND METHODS}

The experiments on pretreatment efficiency assessment of contaminated natural water using ultra-filtration method with various pressure membrane elements at the pilot UF plant developed and manufactured by "BMT ltd" from Vladimir city shown in Figure 1.

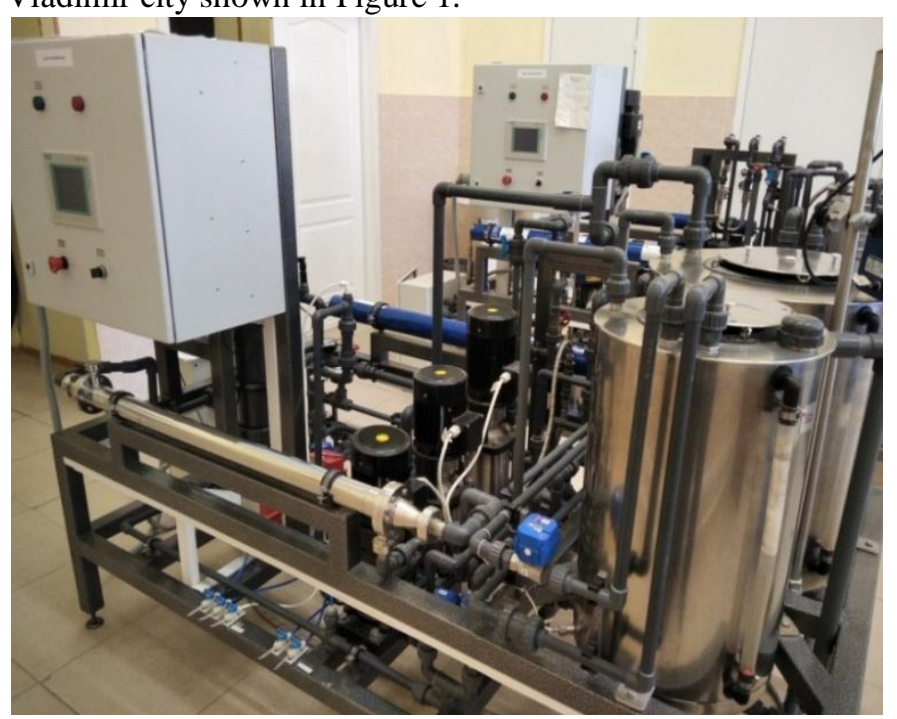

Figure 1. Pilot ultrafiltration plant

Solid waste landfill leachate from Dmitrovsky landfill (Moscow region) was used for testing pressure membrane elements at the pilot ultra-filtration plant as a sample of contaminated natural water. The tests were performed using pressure ceramic membranes of A-Tech (Germany), polysulphone (PS) pressure membranes of MegaVision (China), polyvinylidene fluoride (PVDF) pressure membranes of Inge (Germany). The flow diagram of Ultra-filtration membrane separation process is shown in Figure 2.

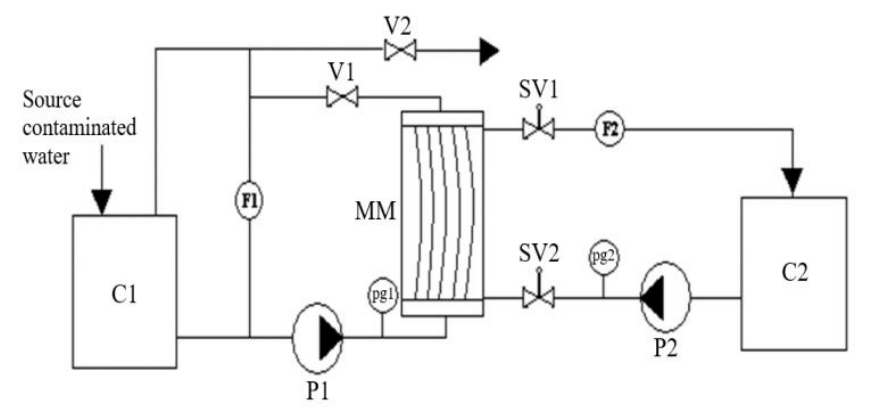

Figure 2. Flow diagram of ultra-filtration membrane separation process

C1, C2 - tank ; F1, F2 - flowmeter; pg1, pg2 - pressure gauge; P1, P2 - pump; MM - membrane module; SV1,SV2 solenoid valve; $\mathrm{V} 1, \mathrm{~V} 2$ - valve
Initial contaminated water from the tank $\mathrm{C} 1$ is pumped by $\mathrm{P} 1$ into the membrane module $\mathrm{MM}$, where the flow is divided into two streams under the operating pressure or discharge: ultra-filtrate - purified from suspended and colloidal particles, petroleums and partially synthetic surfactants (SSAS) and concentrate, enriched with these contaminants, which is continuously returned to the initial tank. The filtrate is collected in an intermediate container $\mathrm{C} 2$. The operating pressure of the separation process is registered by the pressure gauge or pressure vacuum meter pg1.

Determining the qualitative parameters of the initial contaminated water and ultra-filtrates resulted after ultrafiltration membrane separation using various pressure membrane elements was carried out according to the PNDF and GOST methods requirements. The pressure membrane elements were chemically washed after each membrane separation process to restore their transport characteristics.

\section{RESEARCH RESULTS AND DISCUSSION}

The first tested element in a pilot UF plant was A-Tech pressure ceramic element. The initial capacity of the ceramic tubular element for pure fresh water was: $\mathrm{Q}=150 \mathrm{l} / \mathrm{h}$ at $\mathrm{t}=$ $8^{\circ} \mathrm{C}$.

The results of specific filtration rate changes at separation of the initial contaminated natural water using ceramic element are presented in table 1.

Table 1: Specific filtration rate changes at separation of the initial contaminated natural water using ceramic element

\begin{tabular}{|c|c|c|c|}
\hline $\begin{array}{c}\text { Time } \\
\text { min, }\end{array}$ & Capacity, $\mathrm{l} / \mathrm{h}$ & $\begin{array}{c}\text { Specific } \\
\text { filtration rate, } \\
1 / \mathrm{m}^{2} \mathrm{~h}\end{array}$ & $\begin{array}{c}\text { Temperature, } \\
\mathrm{t}^{\circ} \mathrm{C}\end{array}$ \\
\hline 0 & 30 & 57 & 20 \\
\hline 5 & 17 & 32 & 24 \\
\hline 15 & 20 & 38 & 29 \\
\hline 25 & 16 & 30 & 38 \\
\hline 45 & 10 & 19 & 39 \\
\hline
\end{tabular}

Basing on the initial contaminated water volume of 20 liters, and resulting concentrate volume of - 2 liters, the concentration degree (reduction of the initial water volume) was 10 times. After the ultra-filtration separation process, the final performance of the membrane element for pure fresh water was tested - it amounted $11 \mathrm{l} / \mathrm{h}=211 / \mathrm{m}^{2} \cdot \mathrm{h}$ at $\mathrm{t}=5^{\circ} \mathrm{C}$.

To restore the membrane element performance, it was chemically washed with $2 \%$ sodium tripolyphosphate solution during 1 hour, then acidic washing with hydrochloric acid $\mathrm{pH}=2$ and afterwards chemical washing with $2 \%$ sodium tripolyphosphate solution during 1 hour. The ceramic membrane element performance of pure fresh water was 136 $1 / \mathrm{m}^{2} \cdot \mathrm{h}$ at $\mathrm{t}=22^{\circ} \mathrm{C}$. 
At the second research stage, a pressure-type PVDF hollow fiber element was tested. The initial element capacity for pure fresh water was: $\mathrm{Q}=41 \mathrm{l} / \mathrm{h}$ at $\mathrm{t}=17^{\circ} \mathrm{C}$. The results of specific filtration rate changes in separating the initial contaminated natural water using PVDF hollow fiber element at the ultrafiltration plant are presented in table 2.

Table 2: Specific filtration rate changes in separating the initial contaminated natural water using PVDF hollow fiber element

\begin{tabular}{|c|c|c|c|}
\hline $\begin{array}{l}\text { Time } \\
\text { min, }\end{array}$ & $\begin{array}{c}\text { Capacity, } \\
\text { l/h }\end{array}$ & $\begin{array}{c}\text { Specific } \\
\text { filtration } \\
\text { rate, } 1 / \mathrm{m}^{2} \mathrm{~h}\end{array}$ & $\begin{array}{c}\text { Temperature, } \\
\mathrm{t}^{\circ} \mathrm{C}\end{array}$ \\
\hline 0 & 13.2 & 110 & 20 \\
\hline 5 & 9.6 & 80 & 20 \\
\hline 10 & 8.2 & 69 & 21 \\
\hline 16 & 7.7 & 64 & 22 \\
\hline 23 & 6.7 & 56 & 23.5 \\
\hline 30 & 5.5 & 46 & 26 \\
\hline 40 & 3.6 & 30 & 29 \\
\hline 52 & 3.96 & 30 & 31 \\
\hline 50 & 2.64 & 22 & 32 \\
\hline 63 & 2.4 & 20 & 33 \\
\hline
\end{tabular}

The concentration degree was by 11 times (initial contaminated water volume - 11 liters, the volume of the resulting concentrate-1 liter). The final membrane element performance for pure fresh water was checked after the separation process - it was $10 \mathrm{l} / \mathrm{h}$ at $\mathrm{t}=6^{\circ} \mathrm{C}$. To restore the membrane element performance, it was subjected to chemical washing by $2 \%$ sodium tripolyphosphate solution during 1 hour. The washing solution was drained and the element performance was tested for pure fresh water it amounted 25.4 $\mathrm{l} / \mathrm{h}$ at $\mathrm{t}=15^{\circ} \mathrm{C}$.

At the third research stage PS hollow fiber element made of pressure type was tested. The element initial capacity for pure fresh water was $18 \mathrm{l} / \mathrm{h}$ at $\mathrm{t}=8^{\circ} \mathrm{C}$. The results of specific filtration rate changes at separation of the source contaminated natural water using PS hollow fiber element are presented in table 3 .
Table 3: Specific filtration rate changes at separation of the source contaminated natural water using PS hollow fiber element

\begin{tabular}{|c|c|c|c|}
\hline $\begin{array}{l}\text { Time } \\
\text { min, }\end{array}$ & $\begin{array}{l}\text { Capacity, } \\
\text { l/h }\end{array}$ & $\begin{array}{l}\text { Specific filtration } \\
\text { rate, } 1 / \mathrm{m}^{2} \mathrm{~h}\end{array}$ & $\begin{array}{c}\text { Temperature, } \\
\mathrm{t}^{\circ} \mathrm{C}\end{array}$ \\
\hline 0 & 13.6 & 80 & 20 \\
\hline 5 & 11.39 & 67 & 20 \\
\hline 10 & 10.37 & 61 & 21 \\
\hline 20 & 8.84 & 52 & 23 \\
\hline 32 & 7.31 & 43 & 23.5 \\
\hline 45 & 5.58 & 41 & 26 \\
\hline 53 & 4.93 & 29 & 29 \\
\hline 61 & 3.57 & 21 & 31 \\
\hline 70 & 3.23 & 19 & 32 \\
\hline
\end{tabular}

The final membrane element performance for pure fresh water was tested after the separation process and it amounted $5 \mathrm{l} / \mathrm{h}$ at $\mathrm{t}=6^{\circ} \mathrm{C}$. To restore the membrane element performance it was subjected to chemical washing by $2 \%$ sodium tripolyphosphate solution during 1 hour. The cleaning solution was drained and the element performance was tested for pure fresh water, and it amounted $13.61 / \mathrm{h}$ at $\mathrm{t}=15^{\circ} \mathrm{C}$.

Table 4 presents qualitative indicators of the source contaminated natural water and ultra-filtrate resulted after testing various pressure membrane elements at the pilot ultrafiltration plant.

Table 4: Qualitative analysis results under various ultrafiltration conditions

\begin{tabular}{|c|c|c|c|c|}
\hline $\begin{array}{c}\text { Indicator, } \\
\text { units }\end{array}$ & $\begin{array}{c}\text { Initial } \\
\text { contaminated } \\
\text { natural water }\end{array}$ & $\begin{array}{c}\text { Ultra- } \\
\text { filtrate } \\
\text { (cera- } \\
\text { mics) }\end{array}$ & $\begin{array}{c}\text { Ultra- } \\
\text { filtrate } \\
\text { (PVDF) }\end{array}$ & $\begin{array}{c}\text { Ultra- } \\
\text { filtrate } \\
\text { (Polysul- } \\
\text { phone) }\end{array}$ \\
\hline $\begin{array}{c}\text { Suspended } \\
\text { matters, mg/l }\end{array}$ & 380 & 0.07 & 0.072 & 0.062 \\
\hline Iron (Fe total), & 10.51 & 4.25 & 2.1 & 2.2 \\
\hline COD, mgO $/ 1$ & 6855 & 3387 & 4950 & 5100 \\
\hline $\begin{array}{c}\text { Anionic } \\
\text { surfactants, mg/l }\end{array}$ & 21.5 & 15 & 16 & 15 \\
\hline $\begin{array}{c}\text { Nonionic } \\
\text { surfactants, mg/l }\end{array}$ & 143 & 19.5 & 23 & 22.9 \\
\hline $\begin{array}{c}\text { Petroleum's. } \\
\text { mg/l }\end{array}$ & 260.7 & 19.4 & 13 & 13.4 \\
\hline Color, dgr. & 17000 & 7000 & 7900 & 7860 \\
\hline
\end{tabular}


The experiments determined that all pressure elements provide high purification degree for suspended substances > $99.9 \%$. For such indicators as chemical oxygen consumption the purification degree is $>29 \%$, total iron $>80 \%$, color $>$ $40 \%$, petroleum's $>90 \%$, non - ionic surfactants $>84 \%$, anionic surfactants $>30 \%$.

Analyzing the elements final performance for the initial contaminated natural water and their capacity for pure fresh water after chemical washings, it was found that the final capacity of pressure tubular ceramic and hollow fiber elements is almost identical. This capacity rate level depends on the resistance of the fouling layer deposited on the membranes surface and inside the membrane element pores. The comparison of performance recovery for pure fresh water after chemical washing demonstrated that polysulphone pressure element $(80 \%)$ revealed the best recovery rate.

Pressure elements based on ceramics and PVDF showed insufficient recovery rate of performance for pure fresh water - $48 \%$ and $34 \%$, respectively. The low recovery degree of these elements performance is explained by the increased adhesion of contaminants to the membranes surface or the pores fouling.

\section{CONCLUSION}

The research has shown that polysulphone pressure membrane elements revealed the best results for the ultrafiltration treatment of contaminated natural waters represented by the solid waste landfill leachate. Ultra-filtration pretreatment using polysulphone pressure membrane elements prior to the Reverse Osmosis separation for highly contaminated aqueous media allows removal of suspended substances by $99.9 \%$, total iron content by $80 \%$, petroleum products by $90 \%$, non-ionic surfactants by $84 \%$, but polysulphone membrane elements are the best to recover their transport characteristics after chemical washing.

\section{ACKNOWLEDGMENTS}

This work was financially supported by project No. 05.607.21.0314 by the Ministry of Science and Higher Education of the Russian Federation (Agreement dated 06.12.2019 No. 075-15-2019-1837) within the framework of the Federal Target Program "Research and Development in Priority Directions for the Development of the Russian Science and Technology Complex for 2014-2020".

The research results were obtained using the scientific equipment of the collective use center "Interregional multidisciplinary and interdisciplinary center for the collective use of promising and competitive technologies in the areas of development and application of domestic achievements in the field of nanotechnology in industry / engineering".

\section{REFERENCES}

1. Y. Huang, X. Feng "Polymer-enhanced ultrafiltration: Fundamentals, applications and recent developments." Journal of Membrane Science 2019, Vol. 58615, pp.53-83. https://doi.org/10.1016/j.memsci.2019.05.037

2. D. Szymański, M. Zielińska, J. A. Dunalska "Microfiltration and ultrafiltration for treatment of lake water during algal blooms." Ecohydrology \& Hydrobiology. 2019, Vol.19, № 3, pp. 351-358.

https://doi.org/10.1016/j.ecohyd.2019.04.003

3. T.A. Trifonova, S.I. Roschina, L.A. Shirkin, O.G. Selivanov, M.E. Ilina "An integrated innovative technology for the treatment of municipal solid waste landfill leachate." Biosciences Biotechnology Research Asia. 2015, Vol.12, № 3, pp. 2481-2488.

https://doi.org/10.13005/bbra/1927

4. K. Konieczny "Disinfection of surface and ground waters with polymeric ultrafiltration membranes." Desalination. 1998, Vol. 119, № 1, pp. 251-258.

5. T.A. Trifonova, L.A. Shirkin, O.G. Selivanov, M.E. Ilina "Assessment of Aqueous Solutions Concentration Efficiency of Mineral Salts and Organic Media Applying Rotary-Film Evaporator for Natural and Waste Water Treatment." International Journal of Emerging Trends in Engineering Research. 2019, Vol.7, № 12, pp. 857-860.

https://doi.org/10.30534/ijeter/2019/227122019

6. P. Tang, B. Liu, Y. Zhang, H. Chang P. Zhou, M. Feng, V. K.Sharma "Sustainable reuse of shale gas wastewater by pre-ozonation with ultrafiltration-reverse osmosis." Chemical Engineering Journal. 2020. Vol. 392, 123743.

https://doi.org/10.1016/j.cej.2019.123743

7. T.A. Trifonova, A.A. Povorov, L.A. Shirkin, O.G. Selivanov, M.E. Ilina 'Evaluating Membrane Separation Effectiveness for Highly Concentrated Aqueous Media Applying Two-stage Reverse Osmosis Plant." International Journal of Emerging Trends in Engineering Research. 2020, Vol.8, № 3, pp. 906-910. https://doi.org/10.30534/ijeter/2020/47832020

8. F. Bu, B.Gao, Q.Yue, X.Shen, W.Wang "Characterization of dissolved organic matter and membrane fouling in coagulation-ultrafiltration process treating micro-polluted surface water." Journal of Environmental Sciences. 2019, Vol.75, pp. 318-324. https://doi.org/10.1016/j.jes.2018.04.015

9. T.A. Trifonova, A.A. Povorov, L.A. Shirkin, O.G. Selivanov, M.E. Ilina "Optimization of membrane reverse osmosis separation for aqueous media characterized by high mineralization." International Journal of Emerging Trends in Engineering Research. 2020, Vol.8, № 4, pp. 1125-1128.

https://doi.org/10.30534/ijeter/2020/47832020 